\title{
Semi-quantitative Evaluation of Urban Landscape Water in Shandong Province of China
}

\author{
Haiyan Deng ${ }^{\mathrm{a}}$, Shisong Qu ${ }^{\mathrm{b}, *}$, Qiang Huang ${ }^{\mathrm{c}}$ \\ School of Resources and Environment, University of Jinan, Jinan 250022, China \\ adenghaiyan199010@126.com, bstu_quss@ujn.edu.cn, 'Huanghqyy@163.com \\ *Corresponding author. Tel: 13153026919; Address: 336, Nanxinzhuang West Road, Jinan, China
}

\begin{abstract}
There are many urban landscape water projects built around Shandong province which improve the local environment in recent years, but how to develop the landscape water in north of China is a challenge and there is no comprehensive evaluation approach. The semi-quantitative evaluation of landscape water is made for 6 cities of Shandong Province respectively in Daming lake of Jinan, Dongchang lake of Liaocheng, Sihuanwuhai of Binzhou, Nansi lake of Jining, Xiao Budong rubber dam of Linyi, Jiashan reservoir of Weifang on the aspects such as water quantity, quality, the ratio of the water surface area to the urban built-up area, biodiversity, the beneficiary population per $1 \mathrm{~km}^{2}$ of water area, cost, the geographic location of landscape water relative to the urban area and comprehensive functions, etc. And then the advantages and disadvantages of the development of the landscape water projects are analyzed as well, consequently, a reference basis is presented for the healthy development of the landscape water projects construction, which is benefit for the sustainable landscape water development and utilization and then promotes the harmonious development in ecology and society of Shandong province.
\end{abstract}

Keywords-urban landscape water; semi-quantitative evaluation; Shandong province.

\section{INTRODUCTION}

With the development of fast industrialization the urbanization in North China, the people demand higher and higher living environment and the water, consequently, has been the essential element of the urban landscape. Landscape and recreation are the main service functions of urban water ecosystems, and the ecological function of water is more obvious than forest, grassland and farmland of the same area[1]. The western countries were devoted to construct the landscape water projects since 1970s[2]. In recent years, landscape water projects have been constructed in many cities of China. There are many landscape water projects with rivers, springs, lakes and oceans in Shandong Province as well. However, the concept of the landscape water is not unified. Peicheng $\mathrm{Li}$ [3] considered that the water with the obvious landscape effect could be the landscape water. Ruxue $\mathrm{Li}[4]$ thought that the landscape water was the natural or artificial water resources such as lake, canal, trench and fountain in urban built-up area. In addition, the evaluation systems for landscape values of lake, river and wetland were constructed, which was the reference for evaluation of urban landscape water [5], but the evaluation index was imperfect.

North China is lack of water and the precipitation is less and mainly concentrated in flood season. The rivers often dry up in dry season, so more engineering measures are need to maintain landscape compared with South China. In the circumstance of water shortage, there are many problems on water landscape construction such as the suitable rate of landscape water to built-up area, cost and the perfect combination between natural water and artificial projects, etc. So a comprehensive evaluation system is necessary to improve the construction and management level of urban landscape water projects in North China.

\section{SEMI-QUANTITATIVE EVALUATION OF URBAN LANDSCAPE WATER IN SHANDONG PROVINCE}

\section{A. Indexes selection}

The evaluation indexes were selected according to the natural, ecological and social characteristics of landscape water. Specifically, natural characteristics indexes consisted of water quality and quantity; ecological characteristics indexes contained the rate of landscape water area to the build up area and biological diversity as well as the social characteristics indexes covered beneficiary of unit water area, cost, relative geographic position and comprehensive functions. The guarantee frequency of landscape water has not been determined so far. Considering landscape water is closely related with life, so it is same with the frequency of domestic water supply, i.e. $90 \%-95 \%$ and the water quality also meets the water quality standard of scenery and recreation area of China (GB12941-91).

The average water year of 2010 was selected as the present year and water quality standard of scenery and recreation area of China (GB12941-91) as the reference to evaluate the quality degree of landscape water projects. The water balance was calculated without considering multi-year regulation, i.e. storage variation was zero. The rate of water area to built-up area was calculated to evaluate the ecological benefit. For example, Nansi Lake locates in the junction of Jinan city of Shandong and Jiangsu province, so the rate of the water area to the total lake area was the index. The beneficiary of unit water area was the population per $\mathrm{km}^{2}$ serviced by the landscape water project. The total cost was the sum of the landscape water supply project cost 
and the maintenance cost. The geographic position was the location of landscape water project relative to the urban area. The comprehensive functions included landscape, flooding control, irrigation, power generation and groundwater recharge, etc.

\section{B. Semi-quantitative evaluation of various landscape water projects}

Each index of various projects was listed in Tab.1 with investigation, calculation and analysis and then evaluated semi-quantitatively. Each index was classified as 3 degrees of high, middle and low. The 3 degrees (d) were showed by $\mathrm{H}, \mathrm{M}$ and $\mathrm{L}$ with the score of $0.9,0.6$ and 0.3 respectively. In addition, the weight values (i) were $0.2,0.2,0.1,0.1,0.1$, $0.1,0.1$, and 0.1 according to the significance of the indexes. The total score of every project was calculated according to the following formula.

$$
S=\Sigma d i
$$

Then all the projects were ranked based on the scores (see Tab.2). The result shows that Daming Lake of Jinan and Nansi Lake of Jining have the best development. The water resource of Daming Lake is from spring flowing with enough water and good quality. It has obvious benefits in ecology and society with large benefited population of unit water area, good relative position and comprehensive functions. However, the limitations of Daming Lake are high indirect cost because huge surface water reservoirs were built to supply water for Jinan to protect spring replacing groundwater, less species and frequent effect of human on Daming Lake. The water resource of Nansi Lake of Jining is natural runoff with abundant water, richest biodiversity and comprehensive functions. Secondly, Si Huan Wu Hai of Binzhou has the better development with the good quality and superior geographic position as well as more comprehensive functions, but the direct cost is higher because the water resource is diverted from the Yellow River. As a whole, the landscape of Daming Lake of Jinan, Nansi Lake of Jining and Si Huan Wu Hai of Binzhou are better

TABLE I. SUMmaRy OF EACH INDEX Of VARIOUS LANDSCAPE WATER PROJECTS

\begin{tabular}{|c|c|c|c|c|c|c|c|}
\hline \multirow{2}{*}{ Characteristics } & \multirow{2}{*}{ Indexes } & \multicolumn{6}{|c|}{ Landscape water projects } \\
\hline & & $\mathrm{P}_{1}$ & $\mathrm{P}_{2}$ & $\mathrm{P}_{3}$ & $\mathrm{P}_{4}$ & $\mathrm{P}_{5}$ & $\mathrm{P}_{6}$ \\
\hline \multirow{2}{*}{ Natural } & $\mathrm{I}_{1}$ & high & low & low & high & middle & middle \\
\hline & $\mathrm{I}_{2}$ & IV & IV & III & $\mathrm{IV} \sim \mathrm{V}$ & III & III IV \\
\hline \multirow{2}{*}{ Ecological } & $\mathrm{I}_{3}$ & $0.15 \%$ & $7.32 \%$ & $9.34 \%$ & $11.66 \%$ & $1.95 \%$ & $9.91 \%$ \\
\hline & $\mathrm{I}_{4}$ & rich & rich & rich & richest & richer & richer \\
\hline \multirow{4}{*}{ Social } & $\mathrm{I}_{5}$ & more & middle & more & more & middle & less \\
\hline & $\mathrm{I}_{6}$ & 942.59 & 13.22 & 4.00 & 0.87 & 1.32 & 12.79 \\
\hline & $\mathrm{I}_{7}$ & high & middle & middle & low & low & low \\
\hline & $\mathrm{I}_{8}$ & urban & urban & urban & Province junction & County junction & urban \\
\hline
\end{tabular}

TABLE II. SEMI-QUANTITATIVE EVALUATION OF VARIOUS LANDSCAPE WATER PROJECTS

\begin{tabular}{|c|c|c|c|c|c|c|c|c|}
\hline \multirow{2}{*}{ Characteristics } & \multirow{2}{*}{ Weight } & \multirow{2}{*}{ Indexes } & \multicolumn{6}{|c|}{ Landscape water projects } \\
\hline & & & $\mathrm{P}_{1}$ & $\mathrm{P}_{2}$ & $\mathrm{P}_{3}$ & $\mathrm{P}_{4}$ & $\mathrm{P}_{5}$ & $\mathrm{P}_{6}$ \\
\hline \multirow{2}{*}{ Natural } & 0.2 & $\mathrm{I}_{1}$ & $\mathrm{H}$ & $\mathrm{L}$ & $\mathrm{L}$ & $\mathrm{H}$ & M & M \\
\hline & 0.2 & $\mathrm{I}_{2}$ & $\mathrm{M}$ & $\mathrm{M}$ & $\mathrm{H}$ & $\mathrm{L}$ & $\mathrm{H}$ & $\mathrm{M}$ \\
\hline \multirow{2}{*}{ Ecological } & 0.1 & $\mathrm{I}_{3}$ & $\mathrm{~L}$ & $\mathrm{M}$ & M & $\mathrm{H}$ & $\mathrm{L}$ & $\mathrm{M}$ \\
\hline & 0.1 & $\mathrm{I}_{4}$ & $\mathrm{~L}$ & $\mathrm{~L}$ & $\mathrm{~L}$ & $\mathrm{H}$ & M & $\mathrm{M}$ \\
\hline \multirow{4}{*}{ Social } & 0.1 & $\mathrm{I}_{5}$ & $\mathrm{H}$ & $\bar{M}$ & $\mathrm{H}$ & $\mathrm{H}$ & $\bar{M}$ & $\mathrm{~L}$ \\
\hline & 0.1 & $\mathrm{I}_{6}$ & $\mathrm{H}$ & M & M & $\mathrm{L}$ & $\mathrm{L}$ & M \\
\hline & 0.1 & $\mathrm{I}_{7}$ & $\mathrm{~L}$ & M & M & $\mathrm{H}$ & $\mathrm{H}$ & $\mathrm{H}$ \\
\hline & 0.1 & $\mathrm{I}_{8}$ & $\mathrm{H}$ & $\mathrm{H}$ & $\mathrm{H}$ & $\mathrm{L}$ & $\mathrm{L}$ & $\mathrm{H}$ \\
\hline \multicolumn{2}{|r|}{ Total score } & & 0.66 & 0.54 & 0.63 & 0.66 & 0.60 & 0.63 \\
\hline \multicolumn{2}{|r|}{ Ranking } & & 1 & 4 & 2 & 1 & 3 & 2 \\
\hline
\end{tabular}

Where, $\mathrm{P}_{1}$ is Daming Lake of Jinan; $\mathrm{P}_{2}$ is Dongchang Lake of Liaocheng; $\mathrm{P}_{3}$ is Si Huan Wu Hai of Binzhou; $\mathrm{P}_{4}$ is Nansi Lake of Jining; $\mathrm{P}_{5}$ is Jiashan reservoir of Weifang; $\mathrm{P}_{6}$ is Xiaobudong rubber dam of Linyi.

$I_{1}$ is water quantity; $I_{2}$ is water quality; $I_{3}$ is the ratio of landscape water area to built-up area; $\mathrm{I}_{4}$ is biodiversity; $\mathrm{I}_{5}$ is comprehensive function; $I_{6}$ is beneficiary unit area (ten thousand $/ \mathrm{km}^{2}$ ); $\mathrm{I}_{7}$ is cost; $\mathrm{I}_{8}$ is geography position relative to the urban area. 


\section{RESULTS AND DISCUSSION}

\section{A. Results}

The evaluation system of landscape water indicator is established initially. The development degree of landscape water projects ranks Daming Lake of Jinan, Nansi Lake of Jining, Si Huan Wu Hai of Binzhou, Xiaobudong Rubber Dam of Linyi, Jiashan Reservoir of Weifang and Dongchang Lake of Liaocheng. The evaluation results correspond to reality to some extent according to the field investigation.

According to the Semi-quantitative evaluation of urban landscape water in Shandong Province, it is shown that the indexes of natural, ecological and social characteristics have critical effects on the development degree of landscape water projects. So reasonable planning of these indexes is significant for sustainable development of landscape water.

\section{B. Discussion}

There are many problems in the development of landscape water projects in North China. How to solve the problems is the key of the sustainable development of current landscape water projects.

(1) Water resource. Landscape water can promote the urban environment quality, but it needs amount of water to replenish the landscape water resources because of the high evaporation (about $1200 \mathrm{~mm}$ ) in North China. Water resource is a serious problem for North China with the sharp contradiction between supply and demand. In karstic region of North China, surface water can easily be recharged into karst water with strong channel leakage. However, some landscape water projects are constructed with artificial anti-seepage techniques, which increases the evaporation, reduces the groundwater recharge and wastes the valuable groundwater as well as makes the water quality worse, so these projects should be forbidden through making related policy. The Changqing Lake of artificial landscape water is the typical case. It was located in the karstic riverway in west of Jinan with big catchment area in the upstream. In the past, the most of runoff in the river was recharged to the groundwater. Now the landscape water project is constructed with anti-seepage techniques. The large surface area was formed and has some surface ecological benefits, but the disadvantages are more obvious. On the contrary, Jiazi Lake of University of Jinan was also located in the karstic riverway with small catchment area. The landscape water project is constructed with anti-seepage techniques. But the reclaimed water with the treatment by the sewage treatment plant is the water resources feed of the project, which not only satisfy the needs of landscape water, but also takes full advantage of reclaimed water resource. In a word, reasonable planning of local water and full use of rain and recycled water are the important approaches to solve the water resource problem.

(2) Landscape water area. Large landscape water area is beneficial to improve urban ecological environment, but it seriously occupies the urban land source and consumes the water with the large amount of evaporation, which is difficult for the water shortage city especially in North China. On the contrary, small landscape water area can save the urban land source and raise the residential rate. However, it locally affects the comprehensive ecological functions of water and the economic development of the urban. So it is extremely important to determine the reasonable landscape water area. Moreover, the comprehensive factors such as natural condition, availability of water and land as well as the development levels of society and economy, etc. have effects on the reasonable landscape water area. So the suitable landscape water projects should be constructed according to the local natural, social and economic conditions.

\section{ACKNOWLEDGMENTS}

This study was supported by the National Natural Science Foundation of China (40972169).

\section{REFERENCES}

[1] Zhang Cheng, Cao Jia-Jie. Some opinions on service function and construction of urban aquatic ecosystem. Water Resources and Hydropower Engineering,41(7), pp.9-13, 2010.

[2] Krausse, Gerald H. Tourism and waterfront renewal: assessing residential perception in Newport. Ocean and Coastal Management, 26(3), pp.179-203, 1995.

[3] Li Pei-Cheng, Cun Dai-Gui. Second remark on scenic water resources. Advances in Water Science, 9(2), pp.176-180,1998.

[4] Li Ru-Xue, Zhang Zhen. Study on development and sustainable utilization of urban landscape water in Liaocheng City. Resource Development \& Market, 24(9), pp.831-833, 2008.

[5] Zhang Ya-Zhuo, Lian Ji-Liang. Study on the landscape value of river-lake wetlands in cities. Journal of Hydraulic Engineering, 42(11), pp.1328-1333, 2011. 